\title{
EMPIRICAL STUDY PADA FAKTOR-FAKTOR YANG MEMPENGARUHI RISIKO SISTEMATIS SAHAM \\ (Studi Kasus Pada Perusahaan yang Bergerak Pada Sektor Keuangan di Bursa Efek Indonesia Tahun 2017-2018)
}

\author{
Rahayu Triastity ${ }^{1)}$ \\ Rina Susanti ${ }^{2}$ \\ ${ }^{1,2)}$ Dosen Fakultas Ekonomi Universitas Slamet Riyadi Surakarta \\ e-mail: ${ }^{1)}$ iburahayusolo@gmail.com \\ 2) my.rinasusanti@gmail.com
}

\begin{abstract}
ABSTRAK
Penelitian ini berjudul Empirical Study pada Faktor - Faktor yang Mempengaruhi Risiko Sistematis Saham (Studi Kasus Pada Perusahaan yang Bergerak pada Sektor Keuangan di Bursa Efek Indonesia Tahun 2017-2018).

Adapun tujuan penelitian ini adalah: 1) Menganalisis signifikansi pengaruh leverage terhadap risiko sistematis saham perusahaan.2) Menganalisis signifikansi pengaruh firm size terhadap risiko sistematis saham perusahaan. 3) Menganalisis signifikansi pengaruh profitabilitas terhadap risiko sistematis saham perusahaan.

Penelitian ini menggunakan metode kuantitatif. Populasi dalam penelitian ini adalah semua perusahaan yang bergerak di bidang keuangan pada Bursa Efek Indonesia Tahun 2018, sedangkan pemilihan sampel dalam penelitian ini menggunakan teknik purphosive sampling yaitu pemilihan sampel berdasarkan kriteria tertentu. Meetodologi penelitian yang akan digunakan dalam penelitian ini adalah: 1) uji instrumen penelitian meliputi uji validitas dan reliabilitas, 2) uji asumsi klasik (uji autokorelasi, uji multikolinearitas, uji heteroskedastisitas, dan uji normalitas), 3) analisis regresi linier berganda. Hasil penelitian diperoleh kesimpulan bahwa leverage, firm size dan profitabilitas secara bersama-sama berpengaruh signifikan terhadap variabel terikat yaitu risiko sistematis saham perusahaan pada sektor keuangan yang listing di bursa efek indonesia tahun 2017-2018.

Kata Kunci: firm size, ROA, leverage, risiko sistematis saham.
\end{abstract}

\section{PENDAHULUAN}

Pendidikan sudah menjadi hal yang sebagai pembentuk budaya dan peradaban manusia. Pendidikan di berbagai belahan dunia mengalami perubahan mendasar dalam era globalisasi. Pengetahuan dan keterampilan semakin dibutuhkan tidak hanya untuk memecahkan berbagai masalah yang semakin rumit, tetapi untuk mengantisipasi masalah yang akan datang sekaligus membangun masa depan yang lebih baik. Pendidikan merupakan faktor utama dalam pembentukan pribadi manusia untuk ke depannya, pendidikan sangat berperan dalam membentuk baik atau buruknya pribadi manusia menurut ukuran normatif. Menyadari akan pentingnya hal tersebut pemerintah sangat serius menangani bidang pendidikan, reformasi pendidikan merupakan respon terhadap perkembangan tuntutan global sebagai suatu upaya untuk mengadaptasikan sistem pendidikan yang mampu mengembangkan sumber daya manusia untuk memenuhi zaman yang sedang berkembang. Oleh karena itu, lembaga pendidikan perlu dikelola secara profesional dengan menerapkan prinsip-prinsip manajemen mutakhir 
untuk memenuhi kebutuhan masyarakat lokal, nasional, dan internasional.

Pendidikan, termasuk di dalamnya adalah perguruan tinggi, merupakan kunci bagi suatu bangsa untuk meningkatkan kualitas sumberdaya manusia dan sekaligus kualitas bangsanya. Pendidikan Tinggi atau Perguruan Tinggi sangatlah penting bagi kita semua. karena tingkat pendidikan yang dicapai harus disesuaikan dengan perkembangan zaman. Perguruan tinggi memiliki beberapa bentuk, diantaranya adalah Perguruan Tinggi Negeri (PTN) dan Perguruan Tinggi Swasta (PTS) yang merupakan bagian dari lembaga pendidikan tinggi. Perbedaan keduanya ada pada pengelolanya, yaitu PTS dikelola oleh pihak swasta sedangkan PTN oleh negara. Kini perbedaan itu bukanlah hitam putih, yang tampak saat ini, PTN dikelola sebagaimana lembaga pendidikan swasta dengan adanya dalih otonomi perguruan tinggi. Meskipun terdapat PTS yang bermasalah, tetapi itu tak bisa digeneralisir. Secara kualitas, ada beberapa PTS yang lebih bermutu daripada PTN ataupun sebaliknya. Terkait permasalahan PTS, kekurangan mahasiswa juga tak terlepas dari sistem penerimaan mahasiswa baru. Memang benar kualitas yang minim mengakibatkan PTS miskin daya tarik, tapi akar persoalan tak sekadar pada tataran kualitas. Meskipun terjadi merger antar-PTS, persoalan kekurangan mahasiswa akan terus terjadi di tengah tuntutan kemandirian pengelolaan dana PTN. Kini banyak PTN yang berlomba-lomba membuka jalur masuk khusus di luar seleksi nasional mahasiswa perguruan tinggi negeri (SNMPTN). Dengan alternatif jalur masuk non-SNMPTN, PTS tanpa disadari berada di ujung tanduk. Apalagi pandangan masyarakat bahwa PTN lebih bergengsi belumlah menghilang. Kuliah di PTN menimbulkan prestise tersendiri dalam interaksi sosial di tengah masyarakat. Di tempat pekerjaan pun, lulusan PTN masih diposisikan lebih tinggi daripada lulusan PTS. Selain bersaing dengan PTN, PTS juga saat ini menghadapi begitu banyak kompetitor dari sesama PTS.

Perkembangan pendidikan yang sedemikian rupa menyebabkan persaingan menjadi semakin kompetitif antara PTS. Berbagai strategi dapat ditempuh oleh para pelaku bisnis di bidang ini untuk dapat memenangkan persaingan. Untuk dapat bersaing dalam industri kependidikan, Persaingan dalam bisnis pendidikan khususnya dalam menjaring mahasiswa baru sangatlah ketat. Hal ini ditandai dengan banyaknya PTS yang terdapat di setiap daerah dengan daya tarik yang beragam. Sehingga dalam hal ini PTS harus mampu melakukan inovasi dan kreativitas agar bisnis yang dijalankan tetap mendapat perhatian dari masyarakat. Perguruan tinggi yang terdapat di eks Karisidenan Kota Surakarta saat ini beragam dan sudah banyak berkembang dengan beragam jenis jurusan dan program studi. Untuk PTS yang berada di daerah eks Karisidenan Kota Surakarta dan sekitarnya saja sudah terdapat 50 (lima puluh) Perguruan Tinggi dan tentunya mereka akan saling bersaing dalam mendapatkan mahasiswa baru.

Program Studi Manajemen Fakultas Ekonomi merupakan salah satu fakultas yang dikelola oleh Universitas Slamet Riyadi Surakarta. Di Universitas Slamet Riyadi Surakarta saat ini memiliki 6 (enam) fakultas, yaitu Fakultas Ekonomi, Fakultas Hukum, Fakultas KIP, Fakultas Ilmu Sosial dan Ilmu Politik, Fakultas Teknologi Pertanian dan Fakultas Pertanian. Selain persaingan dengan PTN, dalam 
upayanya memperoleh mahasiswa, Fakultas Ekonomi Program Studi Manajemen Universitas Slamet Riyadi Surakarta juga harus menghadapi kompetitor yang serupa, yakni yang bergerak di bidang ekonomi juga.

Jumlah mahasiswa yang mendaftar ke Fakultas Ekonomi Program Studi Manajemen Universitas Slamet Riyadi Surakarta mengalami peningkatan, hal tersebut disebabkan adanya strategi pemasaran yang dilakukan oleh Program Studi Manajemen melalui startegi bauran pemasaran (marketing mix). Strategi marketing mix. "Marketing mix terdiri dari empat variabel yang disebut 4P: product (produk), price (harga), place (tempat), promotion (promosi)" (Kotler, 2012: 62).

Jumlah mahasiswa Fakultas Ekonomi Program Studi Manajemen Universitas Slamet Riyadi Surakarta tahun 2015-2017 mengalami tren peningkatan yang baik, pada tahun 2015 jumlah mahasiswa secara keseluruhan sebanyak 144 orang, pada tahun 2016 meningkat menjadi 202 mahasiswa, pada tahun 2017 juga mengalami peningkatan sebesar 272 mahasiswa. Peningkatan jumlah mahasiswa pada program studi manajemen tersebut dipengaruhi oleh beberapa faktor, salah satunya adalah strategi pemasaran yang dilakukan tim marketing Fakultas Ekonomi Program Studi Manajemen Universitas Slamet Riyadi Surakarta.

Adapun tujuan penelitian ini adalah: 1) Menganalisis signifikansi pengaruh produk terhadap keputusan pemilihan Fakultas Ekonomi Program Studi Manajemen Universitas Slamet Riyadi Surakarta. 2) Menganalisis signifikansi pengaruh harga terhadap keputusan pemilihan Fakultas Ekonomi Program Studi Manajemen Universitas Slamet Riyadi Surakarta. 3) Menganalisis signifikansi pengaruh lokasi terhadap keputusan pemilihan Fakultas Ekonomi Program Studi Manajemen Universitas Slamet Riyadi Surakarta. 4) Menganalisis signifikansi pengaruh promosi terhadap keputusan pemilihan Fakultas Ekonomi Program Studi Manajemen Universitas Slamet Riyadi Surakarta.

\section{KERANGKA PEMIKIRAN}

Kerangkan pemikiran dalam penelitian ini adalah sebagai berikut:

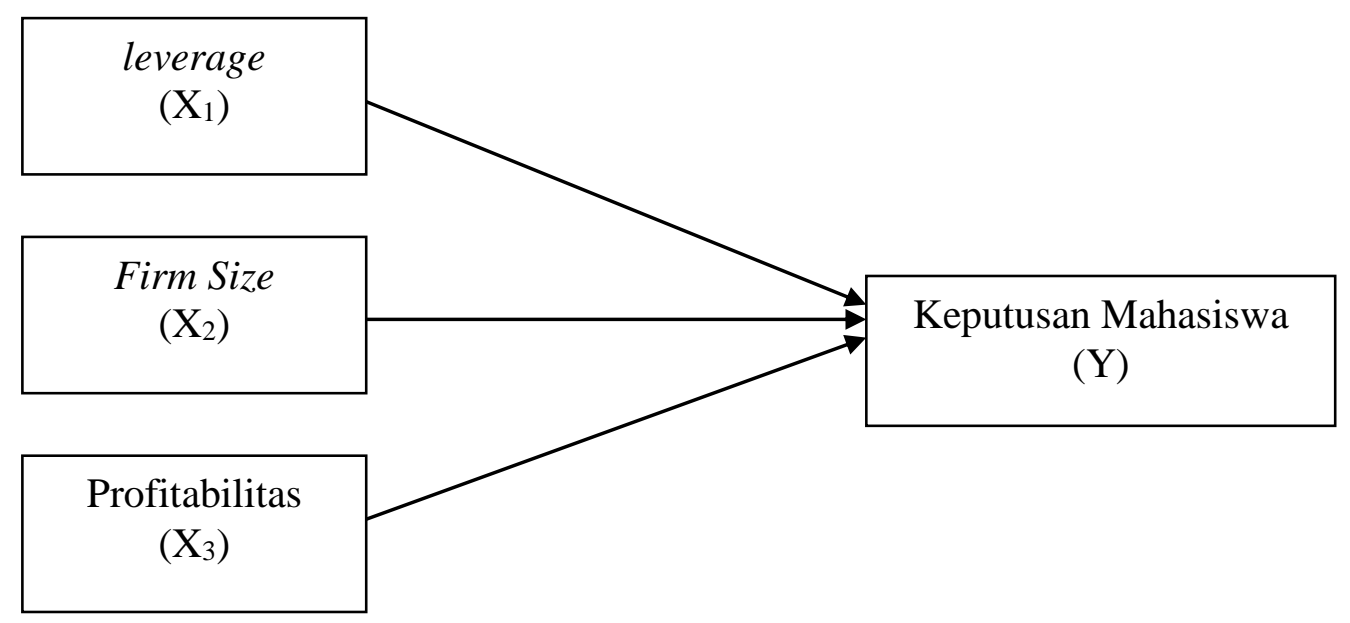

Gambar 1. Skema Karangka Pemikiran 
Dari skema kerangka pemikiran di atas, telihat bahwa terdapat dua variabel, yaitu:

1. Variabel Independen (Variabel Bebas)

Variabel bebas adalah variabel yang mempengaruhi atau menjadi sebab perubahannya atau timbulnya variabel dependen (terikat). Sebagai variabel bebas dalam penelitian ini adalah produk, harga, lokasi dan promosi

2. Variabel Dependen (Variabel Terikat)

Variabel terikat adalah variabel yang dipengaruhi oleh variabel bebas. Sebagai variabel terikat dalam penelitian ini adalah keputusan mahasiswa.

\section{HIPOTESIS}

Agar penelitian ini lebih terarah dan dapat mencapai hasil yang diharapkan, maka penulis mengemukakan hipotesis sebagai berikut:

H1 : Firm size berpengaruh signifikan terhadap risiko sistematis saham.

$\mathrm{H} 2$ : Leverage berpengaruh signifikan terhadap risiko sistematis saham.

H3 : Profitabilitas berpengaruh signifkan terhadap risiko sistematis saham.

\section{METODE PENELITIAN}

Data yang digunakan dalam penelitian ini adalah data sekunder, yaitu data yang dikumpulkan dari
Indonesian Capital Market Directory (ICMD) tahun 2017-2018, terminal bloomberg dan www.idx.co.id, dan berbagai sumber data keuangan lainnya. Adapun populasi dalam penelitian ini adalah seluruh perusahaan yang bergerak pada sektor keuangan di Bursa Efek Indonesia tahun 2017-2018. Selanjutnya pemilihan sampel dilakukan dengan metode purposive sampling yaitu pemilihan sampel berdasarkan kriteria-kriteria sebagai berikut:

1. Tercatat sebagai saham aktif yang listing di BEI pada tahun 2017-2018

2. Menerbitkan laporan keuangan dan laporan tahunan selama periode waktu penelitian dan dimuat dalam Indonesian Capital Market Directory (ICMD).

3. Memperoleh laba selama periode penelitian 2017-2018

4. Memiliki rasio leverage sebagai salah satu rasio pengukuran.

5. Tidak terdapat data outlier pada data sampel yang digunakan dalam penelitian.

Pemilihan data dengan teknik purposive sampling dilakukan karena adanya beberapa syarat yang harus dipenuhi oleh saham-saham yang akan dipilih sebagai sampel penelitian sebagaimana disebutkan diatas, sehingga dapat terpenuhi sampel yang sesuai dengan kebutuhan penelitian. Pengumpulan data dilakukan dengan pooling down (penggabungan antara time series dan cross sectional). 
Teknik analisis data menggunakan:

1. Uji Asumsi Klasik

a. Uji multikolinearitas bertujuan mendeteksi adanya multikolinearitas dengan melihat nilai tolerance dan Varians Inflation Factor (VIF) yang dilakukan dengan bantuan komputer program SPSS.

b. Uji autokorelasi dilakukan dengan uji Run bertujuan untuk melihat apakah data residual terjadi secara random atau tidak.

c. Uji heteroskedastisitas dilakukan dengan uji Glejser, yaitu dengan cara meregres nilai absolut residual terhadap variabel independen.

d. Uji normalitas atas residual dilakukan dengan uji Kolmogorov-Smirnov melalui alat bantu komputer program SPSS 21.

\section{Pengujian Hipotesis}

Teknik analisis data yang digunakan adalah analisis regresi linier berganda, uji t, uji $\mathrm{F}$ dan koefisien determinasi.

\section{HASIL PENELITIAN}

\section{Hasil Uji Asumsi Klasik}

Untuk mengetahui apakah model regresi linear berganda dalam penelitian ini benar-benar menunjukkan hubungan yang signifikan dan representatif atau BLUE (Best Linear Unbiased Estimator) dilakukan pengujian asumsi klasik dengan hasil seperti tabel 3 di bawah ini.

\section{Tabel 3: Hasil Uji Asumsi Klasik}

\begin{tabular}{lll}
\hline \multicolumn{1}{c}{ Uji Asumsi Klasik } & \multicolumn{1}{c}{ Hasil Uji } & \multicolumn{1}{c}{ Kesimpulan } \\
\hline Uji multikolinearitas & Tolerance: 0,$723 ; 0,997 ; 0,724>0,10$ & Tidak ada multikolinearitas \\
& VIF $: 1,383 ; 1,003 ; 1,382 ;<10$ & \\
\hline Uji autokorelasi & p: $0,879>0,05$ & Tidak ada autokorelasi \\
\hline Uji heteroskedastisitas & p: 0,$222 ; 0,647 ; 0,094 ;>0,05$ & Tidak ada heteroskedastisitas \\
\hline Uji normalitas & P: $0,217>0,05$ & Residual berdistribusi normal \\
\hline
\end{tabular}

Sumber : Data keuangan yang diolah, 2017-2018

4. Analisis Regresi Linier Berganda

Hasil analisis regresi linier berganda ditunjukkan dalam tebel 4 sebagai berikut:

Tabel 4: Hasil Analisis Regresi Linier Berganda

\begin{tabular}{lccc}
\hline \multicolumn{1}{c}{ Variabel } & $\mathrm{B}$ & $\mathrm{T}$ & Sig. \\
\hline (Constant) & -0.765 & & 0.190 \\
Firm Size & 0.005 & 0.364 & 0.718 \\
ROA & 4.265 & 2.596 & 0,013 \\
Leverage & 0.805 & 1.626 & 0,112 \\
\hline
\end{tabular}

Adjusted R Square $=0,140$

Sig. F $=0,029$

Sumber : Data keuangan yang diolah, 2017-2018 
Berdasarkan hasil analisis regresi linier berganda diperoleh persamaan garis regresinya sebagai berikut:

$\mathrm{Y}=-0.765+0,005 \mathrm{X}_{1}+4.265 \mathrm{X}_{2}+0.805 \mathrm{X}_{3}+\mathrm{e}$

Interpretasi dari persamaan regresi tersebut adalah:

a : -0.765 artinya jika firm size $\left(\mathrm{X}_{1}\right)$, ROA $\left(\mathrm{X}_{2}\right)$, dan leverage $\left(\mathrm{X}_{3}\right)$ sama dengan nol, maka risiko sistematis saham (Y) adalah negatif.

$b_{1}: 0,005$ artinya pengaruh variabel firm size $\left(\mathrm{X}_{1}\right)$ terhadap risiko sistematis saham (Y) positif, artinya apabila firm size perusahaan tinggi maka risiko sistematis perusahaan pun akan meningkat, dengan asumsi variabel ROA $\left(\mathrm{X}_{2}\right)$ dan leverage $\left(\mathrm{X}_{3}\right)$ dianggap tetap.

$\mathrm{b}_{2}: 4.265$ artinya pengaruh variabel ROA $\left(\mathrm{X}_{2}\right)$ terhadap risiko sistematis saham (Y) positif, artinya apabila ROA perusahaan tinggi, maka risiko sistematis saham juga meningkat, dengan asumsi variabel firm size $\left(\mathrm{X}_{1}\right)$, dan leverage $\left(\mathrm{X}_{3}\right)$ dianggap tetap.

$\mathrm{b}_{3}: 0,805$ artinya pengaruh variabel leverage $\left(\mathrm{X}_{3}\right)$ terhadap risiko sistematis saham (Y) positif, artinya apabila leverage perusahaan tinggi maka risiko sistematis saham juga akan meningkat, dengan asumsi variabel firm size $\left(\mathrm{X}_{1}\right)$, dan ROA $\left(\mathrm{X}_{2}\right)$ dianggap tetap.
Berdasarkan hasil analisis, maka variabel yang dominan pengaruhnya terhadap risiko sistematis saham perusahaan yang bergerak di sektor keuangan Bursa Efek Indonesia adalah variabel ROA $\left(\mathrm{X}_{1}\right)$, karena nilai koefisien regresi paling besar yaitu 4,265 di antara koefisien regresi variabel bebas yang lain yaitu firm size $\left(\mathrm{X}_{1}\right)$ sebesar 0,005 dan harga $\left(X_{2}\right)$ sebesar 0,805 .

\section{Uji t}

a. Pengujian signifikansi pengaruh firm size $\left(\mathrm{X}_{1}\right)$ terhadap risiko sistematis saham (Y)

Hasil analisis diperoleh probabilitas value sebesar $0,718<0,05$ maka Ho diterima yang berarti tidak ada pengaruh yang signifikan firm size $\left(\mathrm{X}_{1}\right)$ terhadap risiko sistematis saham perusahaan yang bergerak di sektor finance (Y). Dengan demikian hipotesis 1 yang menyatakan bahwa: "firm size berpengaruh signifikan terhadap risiko sistematis saham", ditolak atau tidak terbukti kebenarannya.

b. Pengujian signifikansi ROA (X2) terhadap risiko sistematis saham (Y)

Hasil analisis diperoleh probabilitas value sebesar $0,013<0,05$ maka Ho ditolak berarti ada pengaruh yang 
signifikan ROA $\left(\mathrm{X}_{2}\right)$ terhadap risiko sistematis saham (Y). Dengan demikian hipotesis 2 yang menyatakan bahwa: "ROA berpengaruh signifikan terhadap risiko sistematis saham", diterima atau terbukti kebenarannya.

c. Pengujian signifikansi pengaruh leverage $\left(\mathrm{X}_{3}\right)$ terhadap risiko sistematis saham $(\mathrm{Y})$

Hasil analisis diperoleh probabilitas value sebesar $0,112<0,05$ maka Ho terima berarti tidak ada pengaruh yang signifikan leverage $\left(\mathrm{X}_{3}\right)$ terhadap risiko sistematis saham (Y). Dengan demikian hipotesis 3 yang menyatakan bahwa: "leverage berpengaruh signifikan terhadap risiko sistematis saham", ditolak atau tidak terbukti kebenarannya.

\section{Uji F (Uji Ketepatan Model)}

Hasil analisis diperoleh $\mathrm{F}$ hitung sebesar 3.341 dengan p-value sebesar $0,029<0,05$ maka Ho ditolak berarti model yang digunakan untuk menguji pengaruh variabel bebas yaitu firm size $\left(\mathrm{X}_{1}\right)$, ROA $\left(\mathrm{X}_{2}\right)$, dan leverage $\left(\mathrm{X}_{3}\right)$ terhadap variabel terikat yaitu risiko sistematis saham perusahaan yang bergerak pada sektor keuangan di Bursa Efek Indonesia.

\section{Koefisien Determinasi}

Berdasarkan hasil perhitungan diperoleh nilai Adjusted $R$ Square =
0,140 berarti diketahui bahwa pengaruh yang diberikan oleh variabel bebas yaitu firm size $\left(\mathrm{X}_{1}\right)$, ROA $\left(X_{2}\right)$, dan leverage $\left(X_{3}\right)$ terhadap risiko sistematis saham sebesar $14 \%$ sedangkan sisanya $(100 \%-14 \%)=86 \%$ dipengaruhi oleh faktor-faktor lain di luar variabel yang diteliti, terutama pada variabel makro ekonomi seperti inflasi, tingkat suku bunga, dan sebagainya.

\section{PEMBAHASAN}

1. Pengaruh firm size terhadap risiko sistematis saham perusahaan yang bergerak pada sektor keuangan di Bursa Efk Indonesia tahun 20172018.

Hasil analisis diperoleh probabilitas value sebesar $0,718<$ 0,05 maka Ho diterima berarti tidak ada pengaruh yang signifikan firm size $\left(X_{1}\right)$ terhadap risiko sistematis saham (Y). Dengan demikian hipotesis 1 yang menyatakan bahwa: "firm size berpengaruh signifikan terhadap risiko sistematis saham", ditolak atau tidak terbukti kebenarannya.

Hasil penelitian ini berbeda dengan hasil penelitian yang dilakukan oleh Rowe \& Kim (2010), Andayani, S, \& Susanto (2010), Biase \& D‘Apolito (2012), CheeWooi \& Chyn-Hwa (2010), Iqbal \& Shah (2009), Adhikari (2015), Hamzah (2005), J. S. Lee \& Jang (2007) yang menyatakan firm size 
berpengaruh signifikan terhadap risiko sistematis saham. Perbedaan terletak pada objek dan kondisi penelitian yaitu pada beberapa perusahaan di luar negeri dalam kondisi krisis firm size dapat mempengaruhi risiko sistematis saham. Di Indonesia diluar kondisi krisis pada perusahaan yang bergerak di sektor keuangan firm size tidak berpengaruh terhadap harga saham perusahaan.

2. Pengaruh ROA terhadap risiko sistematis saham perusahaan yang bergerak pada sektor keuangan di Bursa Efk Indonesia tahun 20172018.

Hasil analisis diperoleh probabilitas value sebesar $0,013<$ 0,05 maka Ho ditolak berarti ada pengaruh yang signifikan ROA $\left(\mathrm{X}_{2}\right)$ terhadap risiko sistematis saham (Y). Dengan demikian hipotesis 2 yang menyatakan bahwa: "ROA berpengaruh signifikan terhadap risiko sistematis saham", diterima atau terbukti kebenarannya.

Berdasarkan penjelasan secara teori dan hasil penelitian dapat disimpulkan bahwa sesuai dengan hipotesis, variabel ROA berpengaruh positif dan signifikan terhadap risiko sistematis saham. Hal ini berkaitan dengan laba perusahaan atas nilai asset mampu mempengaruhi risiko sistematis saham perusahaan. Semakin tinggi nilai ROA maka risiko sistematis juga semakin tinggi. Hasil penelitian ini juga diperkuat dengan penelitian terdahulu yang dilakukan oleh Biase \& D‘Apolito (2012) yang menunjukkan bahwa ROA berpengaruh terhadap harga saham perusahaan yang bergerak di sektor perbankan di Italia.

3. Pengaruh leverage risiko sistematis saham perusahaan yang bergerak pada sektor keuangan di Bursa Efk Indonesia tahun 2017-2018.

Hasil analisis diperoleh probabilitas value sebesar $0,112<$ 0,05 maka Ho terima berarti tidak ada pengaruh yang signifikan leverage $\left(\mathrm{X}_{3}\right)$ terhadap risiko sistematis saham (Y). Dengan demikian hipotesis 3 yang menyatakan bahwa: "leverage berpengaruh signifikan terhadap risiko sistematis saham", ditolak atau tidak terbukti kebenarannya.

Hasil penelitian ini berbeda dengan penelitian yang dilakukan oleh Hamzah (2005), J. S. Lee \& Jang (2007), Alaghi (2013), Biase \& D‘Apolito (2012), C. L. Lee, Robinson, \& Reed (2008), C. Lee \& Hooy (2012) yang menunjukkan bahwa leverage berpengaruh signifikan terhdap risiko sistematis saham. Perbedaan terletak pada objek dan kondisi penelitian yaitu pada beberapa perusahaan di luar negeri dalam kondisi krisis firm size dapat mempengaruhi risiko sistematis saham. Di Indonesia 
Research Fair Unisri 2019

Vol 4, Number 1, Januari 2020
P- ISSN: 2550-0171

E- ISSN: 2580-5819 diluar kondisi krisis pada perusahaan yang bergerak di sektor keuangan firm size tidak berpengaruh terhadap harga saham perusahaan.

\section{KESIMPULAN}

Hasil penelitian diperoleh kesimpulan bahwa ROA adalah satusatunya variabel independen penelitian yang berpengaruh terhadap risiko sistematis saham perusahaan yang bergerak pada sektor keuangan di Bursa Efek Indonesia Tahun 2017-2018, sedangkan variabel lainnya yaitu firm size dan leverage tidak berpengaruh terhadap risiko sistematis saham. Hal ini berbeda dengan beberapa hasil penelitian sebelumnya diantaranya penelitian Rowe \& Kim (2010) dengan mengambil objek penelitian pada perusahaan casino di AS, Biase \& D‘Apolito (2012) dengan mengambil objek pada perusahaan perbankan di Italia, Chee-Wooi \& Chyn-Hwa (2010) dengan mengambil objek perusahaan penerbangan di Amerika, Eropa, dan Asia, serta beberapa peneliti lainnya yang menyarakan bahwa risiko sistematis saham banyak di pengaruhi oleh vaktor internal yaitu variabel keuangan perusahaan.

Perusahaan yang bergerak pada sektor keuangan di Indonesia banyak dipengaruhi oleh faktor makro dengan kondisi ekonomi yang kurang stabil diantaranya inflasi, nilai suku bunga, nilai tukar rupiah dan yang lainnya. Dengan demikian disarankan untuk peneliti selanjutnya agar menambahkan variabel makro ekonomi sebagai faktorfaktor yang mempengaruhi risiko sistematis saham.

\section{DAFTAR PUSTAKA}

Adhikari, N. (2015). Determinants of Systemic Risk for Companies, 15(5).

Alaghi, K. (2013). Determinants of Systematic Risk of the Listed Companies in Tehran Stock Exchange. Journal of Basic and Applied Scientific Research, 3(1), 596-600.

Al-qaisi, K. M. (2011). The Economic Determinants of Systematic Risk in the Jordanian Capital Market, 2(20), 85-95.

Andayani, N. S. D., S, M. P., \& Susanto, M. H. (2010). Pengaruh Variabel Internal Dan Eksternal Kondisi Pasar Yang Berbeda ( Studi Pada Saham-Saham Ilq 45 Di Bursa Efek Jakarta ). WACANA Vol. 13 No. 2 April 2010 ISSN. 1411-0199, 13(2), 244-259.

Biase, P. Di, \& D‘Apolito, E. (2012). The Determinants of Systematic Risk in the Italian Banking System: A Cross-Sectional Time Series Analysis. International Journal of Economics and Finance, 4(11), 152-164. http://doi.org/10.5539/ijef.v4n11p1 52

Boz, G., Menéndez-Plans, C., \& OrgazGuerrero, N. (2015). "The systematic-risk determinants of the European accommodation and food services industry in the period 2003-2011": Corrigendum. Cornell Hospitality Quarterly, 56(2), 232. http://doi.org/10.1177/1938965515 578145

Chee-Wooi, H., \& Chyn-Hwa, L. (2010). The Determinants of 
Systematic Risk Exposures of Airline Industry in East Asia. World Applied Sciences Journal 10 (Special Issue of Tourism \& Hospitality): 91-98, 2010 ISSN 1818-4953, 10, 91-98.

Grahani, H. A., \& Pasaribu, R. B. F. (2013). ANALISIS FAKTORFAKTOR YANG. Proceding PESAT (Psikologi, Ekonomi, Sastra, Arsitektur \& Teknik Sipil), 5(ISSN 1858-2559), 2-11.

Gu, Z., \& Kim, H. (2002). Determinants of Restaurant Systematic Risk: A Reexamination. The Journal of Hospitality Financial Management, 10(1), 1-13. http://doi.org/10.1080/10913211.2 002.10653757

Hamzah, A. (2005). 367. SNA VIII Solo, 15 - 16 September 2005, (September), 15-16.

Husna, N. (2016). No Title No Title. EJurnal Apresiasi Ekonomi Volume 4 Nomor 1 Januari 2016: 65-70, 4(2337-3997), 65-70. http://doi.org/10.1017/CBO978110 7415324.004

Iqbal, M. J., \& Shah, S. Z. A. (2009). Determinants of systematic risk. The Journal of Commerce Vol. 4 No. 1 ISSN 2218-8118, 2220-6043, 4(1), 47-56.

Kustini, S., \& Pratiwi, S. (2011). PENGARUH DIVIDEND PAYOUT RATIO, RETURN ON ASSET DAN EARNING VARIABILITY TERHADAP BETA SAHAM SYARIAH Sri Kustini, 3(2), 139-148.

Lang, S., \& Scholz, A. (2015). The diverging role of the systematic risk factors: evidence from real estate stock markets. Journal of Property Investment \& Finance, 33(1), 81-106. http://doi.org/10.1108/JPIF-052014-0032
Lee, C., \& Hooy, C. (2012). Journal of Air Transport Management Determinants of systematic fi nancial risk exposures of airlines in North America, Europe and Asia. Journal of Air Transport Management, 24(January 2008), 31-35. http://doi.org/10.1016/j.jairtraman. 2012.06.003

Lee, C. L., Robinson, J., \& Reed, R. (2008). Listed property trusts and downside systematic risk sensitivity. Journal of Property Investment \& Finance, 26(4), 304328.

http://doi.org/http://dx.doi.org/10.1 108/14635780810886627

Lee, J. S., \& Jang, S. (Shawn). (2007). The systematic-risk determinants of the US airline industry. Tourism Management, 28(2), 434-442. http://doi.org/10.1016/j.tourman.20 06.03.012

Lee, W. S., Moon, J., Lee, S., \& Kerstetter, D. (2015). Determinants of systematic risk in the online travel agency industry. Tourism Economics, 21(2), 341-355. http://doi.org/10.5367/te.2013.034 8

Liu, D. (2015). Does Financial Crisis Matter? Systematic Risk in the Casino Industry. The Journal of Global Business Management Volume 11 Number 1 April 2015 Issue, 11(1), 147-155.

Ramasamy, O. \& Y. (2005). Firm Size, Ownership And Performance In The Malaysian Palm Oil Industry. Asian Academy of Management Journal of Accounting and Finance, 1, 104-181. Retrieved from http://myais.fsktm.um.edu.my/668 $5 /$

Rowe, T., \& Kim, J. (2010). Analyzing the Relationship Between 
Systematic Risk and Financial Variables in the Casino Industry. UNLV Gaming Research \& Review Journal, 14(2), 47. Retrieved from http://proquest.umi.com/pqdweb?d $\mathrm{id}=2203784791 \& \mathrm{Fmt}=7 \&$ clientId $=$ $143891 \& \mathrm{RQT}=309 \& \mathrm{VName}=\mathrm{PQ}$ D

Saragih, dkk. 2005. Dasar-Dasar keuangan Bisnis (Teori dan Aplikasi). PT Gramedia: Jakarta.

Schwartz, A. (2005). A Normative Theory of Business Bankruptcy. Yale Law School Legal Scholarship Repository, 91(1199), 1200-1261.

Sjahrial, Darmawan. 2007. Manajemen Keuangan. Mitra Wacana Media: Jakarta.

Syamsudin, Lukman. 2001. Manajemen Keuangan Perusahaan. PT Raja Grafindo: Jakarta.

Tandelilin, Enduardrus. 2001. Analisis Investasi dan Manajemen Portofolio. PTBEFE: Yogyakarta.

Tandelilin, Enduardrus. 2010. Portofolio dan Investasi Teori dan Aplikasi. Kanisius: Yogyakarta.

Yong \& Rodoni. 2002. Analisis Investasi \& Teori Portofolio. PT Rajagrafindo Persada: Jakarta.

Zadeh, F. O., \& Eskandari, A. (2012). Firm Size As Company', s Characteristic and Level of Risk Disclosure: Review on Theories and Literatures. International Journal of Business and Social Science, 3(17), 9-17.

Zubir, Zalmi. 2011. Manajemen Portofolio (Penerapannya dalam Investasi Saham). Salemba Empat: Jakarta. 